\title{
Alterações bromatológicas nas frações dos carboidratos de silagens de milho "safrinha" sob diferentes tempos de exposição ao ar antes da ensilagem ${ }^{1}$
}

\section{João Pedro Velho ${ }^{2}$, Paulo Roberto Frenzel Mühlbach ${ }^{3}$, Teresa Cristina Moraes Genro ${ }^{4}$, Ione Maria Pereira Haygert Velho ${ }^{5}$, José Laerte Nörnberg ${ }^{6}$, Mariane Garcia Orqis ${ }^{7}$, Julcemar Dias Kessler ${ }^{8}$}

\author{
1 Projeto parcialmente financiado pelo CNPq, com recursos da bolsa prêmio do segundo autor. \\ 2 Doutorando - UFRGS. Bolsista CNPq. \\ ${ }^{3}$ Departamento de Zootecnia - UFRGS. \\ ${ }^{4}$ EMBRAPA Pecuária Sul. \\ ${ }^{5}$ Doutoranda - UFRGS. Bolsista CAPES. \\ ${ }^{6}$ Departamento de Tecnologia de Alimentos - UFSM \\ 7 Graduação em Biologia - URCAMP. Bolsista de Iniciação Científica Embrapa Pecuária Sul. \\ 8 Graduação em Zootecnia - UFSM.
}

RESUMO - Objetivou-se avaliar o efeito da maturidade dos grãos de milho e do tempo de exposição ao ar antes da ensilagem sobre os teores de carboidratos de silagens de milho "safrinha". O experimento foi conduzido em delineamento completamente casualizado com arranjo fatorial $2 \times 4$, no qual foram testados dois estádios de maturidade ao corte (grão completamente leitoso (GL) ou grão $1 / 2$ leitoso e 1/2 farináceo (GF)) e quatro tempos de exposição ao ar, sem compactação $(0,12,24$ ou 36 horas) antes da ensilagem em minissilos. Os cortes das plantas ocorreram nos dias 26/04 e 18/05/2004. Houve efeito significativo dos estádios de maturidade (M) e dos tempos de exposição ao ar (TE), além de interação entre os efeitos, para a maioria das variáveis estudadas. O teor de MS diferiu entre os estádios de maturidade e os tempos de exposição ao ar. As silagens GL e GF, respectivamente, diferiram quanto ao teor de açúcares solúveis $(1,51$ a $1,31 \%$ da MS) e de amido (4,23 a 13,21\% da MS). Quanto aos tempos de exposição ao ar, os açúcares solúveis diminuíram entre os tempos zero (1,64\% da MS) e 36 horas ( $1,05 \%$ da MS). O maior impacto dos TE foi verificado nos teores de fibra em detergente neutro corrigidos para cinzas e proteína (FDNcp). O tempo de exposição ao ar do material verde picado, de 12 horas antes da ensilagem, afetou de modo negativo o valor nutritivo de silagens de milho.

Palavras-chave: açúcares solúveis, amido, FDA, FDN, lignina, MO

\section{Bromatologic changes in the carbohydrate fractions of corn silage from corn crop planted late in the season, under different air exposure time prior to ensiling}

\begin{abstract}
The objective of this experiment was to evaluate the effect of corn grain maturity and air exposure time prior to ensiling on the carbohydrate concentration of corn silage from corn crop planted late in the season. A complete randomized design was used with a $2 \times 4$ factorial arrangement, testing two stages of maturity at harvest (MK - milky kernel and MDK - $1 / 2$ milky and $1 / 2$ dough kernel) of maize crops and four air exposure time prior to ensiling: 0, 12, 24 and 36 hours. Harvests occurred in 2004 on April $26^{\text {th }}$ and May $18^{\text {th }}$. Stage of maturity (M) and periods of air exposure (TE) showed significant effects as well as interactions in most of tested variables. DM content was different according to $\mathrm{M}$ and TE. The MK and MDK silages showed different residual sugar and starch concentrations, respectively, 1.51 and $1.31 \%$ and 4.23 and $13.21 \%$ of DM. Soluble sugars decreased with TE with values of $1.64 \%$ (DM basis) with zero h air exposure to $1.05 \%$ after 36 hours exposure. The greatest impact of TE was observed on NDFap values (NDF corrected for ash and protein). Even a short 12-hour period of air exposure before ensiling affects negatively the nutritional value of corn silages.
\end{abstract}

Key Words: ADF, lignin, NDF, OM, soluble sugars, starch

\section{Introdução}

Segundo Rotz \& Muck (1994), o objetivo primário da conservação de forragens é manter a MS colhida com perdas mínimas dos nutrientes. Estes autores, com base em vários trabalhos, afirmam que as perdas médias na produção de silagem variam de 14 a $24 \%$, de modo que aproximadamente a metade das perdas ocorre durante a estocagem e que, geralmente, a soma das perdas físicas ou a exaustão de nutrientes como os carboidratos solúveis 
ocasionam aumentos de 3 a 12 pontos percentuais no teor de FDN na MS de silagens produzidas e pequena variação, para menos ou para mais, na concentração de proteína.

As técnicas inadequadas de ensilagem (fase aeróbia prolongada e fermentação heterolática ineficiente) e de "desensilagem" (aquecimento) ainda vigentes no nosso meio resultam no desperdício excessivo de glicídios solúveis e no aumento do teor de FDN no produto final (Mühlbach, 2003).

A composição das frações da planta de milho, em virtude de fatores genotípicos e fenotípicos, tem influência direta na qualidade da planta de milho, de modo que as duas frações que mais representam a planta de milho são a FDN e o amido. Qualquer alteração nesses dois parâmetros resulta em grandes alterações no valor nutricional da planta de milho (Dias, 2002). O estádio de maturidade no momento da colheita é determinante do valor nutritivo da silagem (Johnson et al., 1999), observando-se que a digestibilidade da FDN influencia o desempenho animal, independentemente de sua concentração dietética (Oba \& Allen, 2000).

Os quatro principais processos que afetam negativamente o processo de ensilagem são a respiração e atividade enzimática da planta até o fechamento do silo, a atividade clostrídica no processo fermentativo e a atividade microbiana aeróbia na abertura do silo (Muck, 1988). A respiração das plantas durante a colheita ocasiona perdas dos carboidratos solúveis e, conseqüentemente, as concentrações de PB, FDN, FDA, LIG e de outras frações não afetadas pela respiração aumentam em proporção, sendo que parte da proteína verdadeira é convertida a nitrogênio não-protéico (Rotz \& Muck, 1994).

Neste estudo objetivou-se avaliar o efeito da maturidade dos grãos de milho e do tempo de exposição ao ar antes da ensilagem sobre os teores de carboidratos de silagens da planta inteira de milho "safrinha".

\section{Material e Métodos}

O trabalho de campo foi desenvolvido em uma propriedade particular no município de Palmeira das Missões, RS. O solo é classificado como latossolo vermelho distrófico típico LVd3 (Streck et al., 2002) e o clima é do tipo Cfa, subtropical, com verões quentes e chuvas bem distribuídas ao longo do ano, com temperatura média de $22^{\circ} \mathrm{C}$ no período mais quente (Moreno, 1961).

O híbrido triplo AG5011, de ciclo precoce, com grão dentado de cor amarela, é recomendado pela empresa de sementes como híbrido para "safrinha" na Região Sul do país. A semeadura ocorreu em janeiro de 2004, com espaçamento entre linhas de $0,75 \mathrm{~m}$ e o estande final de plantas atingiu 50.000/ha. A adubação de base NPK foi de $250 \mathrm{~kg} / \mathrm{ha}$ da fórmula 08-18-28 e a adubação de cobertura nitrogenada com uréia foi de $100 \mathrm{~kg} / \mathrm{ha}$, dividida em duas aplicações.

A colheita das plantas de milho foi realizada manualmente por meio do corte a $15 \mathrm{~cm}$ do nível do solo de uma lavoura comercial de milho "safrinha" cultivada em sistema de plantio direto. Foram realizadas duas colheitas, a primeira no dia 26 de abril de 2004, quando os grãos apresentavam-se no estádio completamente leitoso (GL), e a segunda em 18 de maio de 2004, quando os grãos atingiram o estádio $1 / 2$ leitoso $1 / 2$ farináceo $(\mathrm{GF})$. A temperatura ambiental média do dia 26 de abril de 2004 foi de $15,9^{\circ} \mathrm{C}$ e, nos dias 27 e 28 (ensilagem), de 18,7 e $20,9^{\circ} \mathrm{C}$, respectivamente. As temperaturas médias nos dias 18 (dia da colheita), 19 e 20 de maio de 2004 (ensilagem) foram de 11,$9 ; 12,2$ e $12,8^{\circ} \mathrm{C}$, respectivamente, segundo dados da estação metereológica de Cruz Alta - RS, do $8^{\circ}$ Distrito de Metereologia.

A colheita das plantas em ambos os estádios de maturidade ocorreu entre as 16 e $18 \mathrm{~h}$ do dia e, no momento dos cortes, foram desprezadas as bordaduras da cabeceira $(5 \mathrm{~m})$ da lavoura de milho, seguindo-se com o corte das demais plantas até atingir aproximadamente $1.000 \mathrm{~kg}$ de matéria verde em cada corte. A seguir, as plantas foram picadas em ensiladeira regulada para tamanho de corte médio de $1,2 \mathrm{~cm}$. Constituindo o tratamento controle, realizaram-se o enchimento e fechamento dos silos logo após a picagem das plantas de milho. A ensilagem foi realizada em mini-silos constituídos de dois sacos plásticos com 12 micras de espessura, sobrepostos. Para facilitar a compactação, efetuou-se o pisoteio nos sacos introduzidos e armados sobre baldes plásticos com capacidade para $20 \mathrm{~L}$. Antes do fechamento dos sacos plásticos (mini-silos), realizou-se sucção com aspirador de pó doméstico para a retirada de eventual ar residual. Após 10 horas da vedação, os mini-silos foram retirados dos baldes e armazenados em sala fechada protegida da radiação solar.

O enchimento e fechamento para os demais tratamentos ocorreram 12, 24 e 36 horas após picagem e exposição do material ao ar, sem compactação. A ensilagem foi realizada ao anoitecer para os tratamentos zero e 24 horas (19 horas) e ao amanhecer (sete horas) para os tratamentos 12 e 36 horas de exposição ao ar antes da ensilagem.

Anteriormente às ensilagens, amostras das plantas verdes (material fresco) de cada tratamento foram coletadas (1 kg de cada tratamento), acondicionadas em sacos plásticos e congeladas a $-18^{\circ} \mathrm{C}$. Dez minutos antes do enchimento dos mini-silos, nos tempos 12, 24 e 36 horas após a picagem, monitorou-se o aquecimento da massa verde 
exposta ao ar sem compactação. Foram utilizados cinco termômetros de mercúrio líquido graduados de um em $1{ }^{\circ} \mathrm{C}$, distribuídos na massa, em diferentes profundidades.

No momento da abertura, desprezaram-se as camadas superiores, inferiores e laterais da silagem de cada mini-silo. Imediatamente à amostragem, determinou-se o teor de matéria parcialmente seca, por meio da secagem de parte do material em estufa de circulação forçada e renovação de ar a $55 \pm 0,1^{\circ} \mathrm{C}$ por 72 horas até peso constante. $O$ restante do material foi armazenado a $-18^{\circ} \mathrm{C}$.

Os teores de MS, MO, FDA, lignina em detergente ácido (ácido sulfúrico), nitrogênio insolúvel em detergente neutro (NIDN) e nitrogênio insolúvel em detergente ácido (NIDA) foram determinados segundo procedimentos descritos por Silva \& Queiroz (2002) utilizando-se amostras trituradas em moinho do tipo Willey com peneira de $1 \mathrm{~mm}$. A determinação da FDN também foi realizada conforme descrito por Silva \& Queiroz (2002), porém optou-se por não utilizar sulfito de sódio na solução em detergente neutro, sendo empregada $\alpha$-amilase. Por isso, a proteína remanescente na FDN foi subtraída após a multiplicação do fator 6,25 pelo teor do NIDN. A abreviação FDNcp expressa o teor de FDN determinado com o uso de $\alpha$-amilase termoestável descontando-se a proteína insolúvel em detergente neutro (PIDN) e as cinzas residuais.

As determinações de açúcares solúveis (Aç. Sol.) e matéria orgânica do resíduo insolúvel em etanol a $80 \%$ (MORIE) foram realizadas conforme Hall (2000) utilizando-se para determinação de amido a metodologia descrita por Walter (2005). Após as determinações bromatológicas, realizaram-se os cálculos do fracionamento dos carboidratos segundo Sniffen et al. (1992).

O experimento foi realizado em delineamento completamente casualizado, em arranjo fatorial 2 x 4 (dois estádios de maturação e quatro tempos de exposição ao ar antes da ensilagem), com quatro repetições por tratamento, considerando-se os mini-silos as unidades experimentais. As análises estatísticas foram realizadas de acordo com o modelo:

$$
Y_{\mathrm{ijk}}=\mu+\alpha_{\mathrm{i}}+\beta_{\mathrm{j}}+(\alpha \beta)_{\mathrm{ij}}+\varepsilon_{\mathrm{ijk}} \text {, }
$$

em que: $\mathrm{Y}_{\mathrm{ijk}}=$ variável resposta; $\mu=$ média geral da variável; $\alpha_{i}=$ efeito do fator estádio do grão de milho, $\mathrm{i}=$ grão completamente leitoso e grão $1 / 2$ leitoso $1 / 2$ farináceo; $\beta_{j}=$ efeito do fator tempo de exposição ao $a r, j=0,12,24$ e 36 horas; $(\alpha \beta)_{\mathrm{ij}}=$ efeito da interação estádio de maturidade do grão de milho x tempo de exposição ao ar; $\varepsilon_{\mathrm{ijk}}=$ erro aleatório.

Os dados das amostras originais foram submetidos somente à análise estatística descritiva e os das silagens, à análise de variância por meio do software SPSS (1999), aplicando-se o teste de comparação entre médias Tukey a $5 \%$ para as variáveis que apresentaram diferença estatís- tica. Os parâmetros que não apresentaram interações foram submetidos à análise de regressão, porém, como os coeficientes de determinação foram muito baixos, não são apresentados neste trabalho.

\section{Resultados e Discussão}

As temperaturas da massa verde após exposição ao ar durante 12, 24 e 36 horas para o GL foram, respectivamente, de 39,$4 ; 38,8$ e $41,6^{\circ} \mathrm{C}$ e, para o GF, de 30,$4 ; 37,8$ e $37,0^{\circ} \mathrm{C}$. Em ambos os estádios, a temperatura da massa ultrapassou significativamente a temperatura média dos dias e, possivelmente, não foi mais alta em virtude das baixas temperaturas ambientais.

A respiração das plantas é incrementada exponencialmente em temperatura de $27^{\circ} \mathrm{C}$ (Rotz \& Muck, 1994). No entanto, segundo Van Soest (1994), a cada aumento de $10^{\circ} \mathrm{C}$, todas as taxas de reações químicas praticamente duplicam. A respiração das plantas após o corte, portanto em déficit fotossintético, causa perdas de MS e carboidratos rapidamente fermentáveis, representando perdas energéticas nas plantas colhidas, além de menor quantidade de substrato para os lactobacilos, diminuindo o valor nutricional da silagem produzida (Muck, 1988).

As maiores diferenças de temperaturas entre a massa verde do GF nos tempos 24 e 36 horas, em relação às temperaturas médias ambientais, possivelmente podem ser explicadas pela afirmação de Ferreira (2001) de que plantas de milho com maiores teores de MS apresentam maior perda na colheita, maior dificuldade de compactação, aquecimento da massa ensilada e menor taxa de fermentação, resultando em silagens de qualidade inferior, principalmente nos silos de superfície. As plantas de milho com teores baixos de MS, por sua vez, apresentam menor produção por hectare, maior perda de nutrientes por lixiviação e redução do valor nutritivo da silagem, resultando, também, em menor consumo de MS. Segundo Senger et al. (2004), o conteúdo de MS assume papel fundamental, aumentando a proporção de nutrientes, facilitando os processos fermentativos ou diminuindo a ação de microrganismos que afetam negativamente o valor nutricional da silagem.

O maior teor de MS (Tabela 1) no GF era esperado, tendo em vista o estádio mais avançado de maturação do grão de milho, cuja diferença significativa $(\mathrm{P}<0,05)$ se refletiu nas respectivas silagens. No entanto, apesar da diferença estatística $(\mathrm{P}<0,05)$ entre os estádios de maturidade, as diferenças ocasionadas pelos tempos de exposição ao ar antes da ensilagem foram de distintas magnitudes.

Os teores de açúcares solúveis (Tabela 2) diminuíram consideravelmente durante os tempos de exposição ao ar de 
12, 24 e 36 horas antes da ensilagem em ambos os estádios, provavelmente em razão da respiração das plantas e/ou da oxidação por microrganismos aeróbios. Porém, a respiração e oxidação não foram suficientes para consumir todos os açúcares solúveis ou a técnica de determinação desses açúcares superestimou os valores. A maior parte dos açúcares solúveis remanescente foi fermentada no processo de transformação em silagem. Entretanto, o efeito maléfico da exposição ao ar ocasionou, com o passar do tempo, diferenças significativas $(\mathrm{P}<0,05)$ no teor final dos açúcares solúveis com o passar do tempo ( 0 a 36 horas) na silagem produzida. A silagem produzida no tratamento 36 horas apresentou 34,7\% menos açúcares solúveis que a silagem produzida imediatamente após a colheita das plantas (tratamento zero hora). Avaliando silagens de milho com $28 \%$ de MS e densidade de compactação de $625 \mathrm{~kg}$ de matéria verde $/ \mathrm{m}^{3}$, Senger et al. (2005) determinaram teor de açúcares solúveis residual na silagem ( $1,8 \%$ na MS) superior aos obtidos neste trabalho, diferindo provavelmente pelo fato de os teores de MS serem diferentes.

Considerando-se os teores de amido descritos na Tabela 2, as inferências devem ser cautelosas, visto que os altos coeficientes de variação podem ter sido ocasionados pela baixa repetibilidade da técnica de determinação ou pela contaminação glicídica das enzimas usadas na metodologia. A fração $B_{1}$ (Tabela 6), que representa o amido do alimento, foi igualmente prejudicada pelo alto coeficiente de variação do teor de amido. Rodrigues et al. (2004), trabalhando com silagens de milho de 35,26 e 44,06\% de MS, obtiveram, respectivamente, 27,04 e 24,46\% de amido na MS, apresen-

Tabela 1 - Teores médios de MS dos materiais originais e das silagens

Table 1 - $\quad$ DM contents of fresh materials and silages

\begin{tabular}{|c|c|c|c|c|c|c|}
\hline \multirow[t]{2}{*}{$\begin{array}{l}\text { Período }{ }^{1} \\
\text { Period }\end{array}$} & \multicolumn{3}{|c|}{$\begin{array}{c}\text { Matéria verde } \\
\text { Fresh material }\end{array}$} & \multicolumn{3}{|c|}{$\begin{array}{l}\text { Silagem } \\
\text { Silage }\end{array}$} \\
\hline & & $\begin{array}{l}\mathrm{GF}^{3} \\
M D K\end{array}$ & $\begin{array}{l}\text { Média } \\
\text { Mean }\end{array}$ & $\begin{array}{l}\mathrm{GL}^{2} \\
M K M\end{array}$ & $\begin{array}{c}\mathrm{GF}^{3} \\
D K\end{array}$ & $\begin{array}{l}\text { Média } \\
\text { Mean }\end{array}$ \\
\hline ero hora (hour) & 23,26 & 30,83 & & & 27,91 & \\
\hline 12 horas (hours) & 22,08 & 29,01 & 25,55 & 20,91 & 26,55 & $23,73 \mathrm{C}$ \\
\hline 24 horas (hours) & 22,99 & 28,36 & 25,68 & 20,82 & 27,88 & $24,35 \mathrm{BC}$ \\
\hline 36 horas (hours) & 23,05 & 27,70 & 25,38 & 21,60 & 28,39 & $25,00 \mathrm{~A}$ \\
\hline Média $(\text { Mean })^{4}$ & 22,85 & 28,98 & 25,92 & $21,34 b$ & $27,68 \mathrm{a}$ & 24,51 \\
\hline $\mathrm{DP}(S D)^{5}$ & 0,52 & 1,35 & 3,41 & 0,64 & 1,12 & 3,36 \\
\hline \multicolumn{7}{|c|}{$\begin{array}{l}1 \text { Tempo de exposição ao ar antes da ensilagem. } \\
2 \text { Grão completamente leitoso. } \\
3 \text { Grão } 1 / 2 \text { leitoso } 1 / 2 \text { farináceo. } \\
4 \text { Médias seguidas por letras diferentes, minúsculas na coluna e maiúsculas } \\
\text { na linha, são estatisticamente }(P<0,05) \text { diferentes. } \\
5 \text { Desvio-padrão. } \\
1 \text { Periods of air exposure prior to ensiling. } \\
2 \text { Milky kernel. } \\
3 \text { 1/2 milky } 1 / 2 \text { dough kernel. } \\
4 \text { Means followed by different small letters in rows and capital letters in columns differ } \\
\text { (P<0.05). }\end{array}$} \\
\hline
\end{tabular}

tando coeficiente de variação considerado baixo $(16,05 \%)$ para esta variável.

O teor de MO (Tabela 2) do resíduo insolúvel em etanol a $80 \%$ sofreu efeito da interação maturidade $\mathrm{x}$ tempo de exposição ao ar, pois, na silagem de GL, aumentou em 4,2 pontos percentuais nas primeiras 12 horas de exposição ao ar, enquanto na de GF o incremento foi de apenas 1,0 ponto percentual. A determinação da MORIE é uma técnica de baixo custo e de fácil aplicação e, segundo Hall et al. (1997), soluções de etanol aquoso têm sido usadas para extrair açúcares simples, oligossacarídeos e outras substâncias de baixo peso molecular de amostras de alimentos prepara-

Tabela 2 - Teores médios de açúcares solúveis, amido e matéria orgânica do resíduo insolúvel em etanol a $80 \%$ da matéria verde e das silagens

Table 2- Average contents of soluble sugars, starch and ethanol insoluble organic matter residue of fresh material and silages

\begin{tabular}{|c|c|c|c|c|c|c|}
\hline \multirow[t]{3}{*}{$\begin{array}{l}\text { Período } \\
\text { Period }\end{array}$} & \multicolumn{3}{|c|}{$\begin{array}{l}\text { Matéria verde } \\
\text { Fresh material }\end{array}$} & \multicolumn{3}{|c|}{$\begin{array}{l}\text { Silagem } \\
\text { Silage }\end{array}$} \\
\hline & $\mathrm{GL}^{2}$ & $\mathrm{GF}^{3}$ & Média & $\mathrm{GL}^{2}$ & $\mathrm{GF}^{3}$ & Média ${ }^{4}$ \\
\hline & $M K$ & $M D K$ & Mean & $M K M$ & $D K$ & Mean \\
\hline
\end{tabular}

Açúcar solúvel (\% da MS)

Soluble sugar (\% of DM)

$\begin{array}{lllllll}0 & 11,66 & 9,37 & 10,52 & 1,68 & 1,60 & 1,64 \mathrm{~A}\end{array}$

$\begin{array}{lllllll}12 & 9,82 & 8,84 & 9,33 & 1,64 & 1,34 & 1,49 \mathrm{AB}\end{array}$

$\begin{array}{lllllll}24 & 9,84 & 4,25 & 7,05 & 1,49 & 1,32 & 1,41 \mathrm{~B}\end{array}$

$\begin{array}{lllllll}36 & 5,02 & 3,43 & 4,23 & 1,15 & 0,98 & 1,07 \mathrm{C}\end{array}$

$\begin{array}{lllllll}\text { Média (Mean) } & 9,09 & 6,47 & 7,78 & 1,49 \mathrm{a} & 1,31 \mathrm{~b} & 1,40\end{array}$

$\begin{array}{lllllll}\mathrm{DP}(S D)^{5} & 2,84 & 3,07 & 3,07 & 1,51 & 0,27 & 0,26\end{array}$

Amido (\% da MS)

Starch $(\%$ of DM)

\begin{tabular}{|c|c|c|c|c|c|c|}
\hline 0 & 5,81 & 11,70 & 8,76 & $3,14 \mathrm{Bb}$ & $14,31 \mathrm{Aa}$ & 8,73 \\
\hline 12 & 5,03 & 13,48 & 9,26 & $2,34 \mathrm{Bb}$ & $14,33 \mathrm{Aa}$ & 8,34 \\
\hline 24 & 6,21 & 11,78 & 9,00 & $4,80 \mathrm{Bb}$ & $13,12 \mathrm{Aa}$ & 8,96 \\
\hline 36 & 5,13 & 12,80 & 8,97 & $7,44 \mathrm{Aa}$ & $11,07 \mathrm{Aa}$ & 9,26 \\
\hline Média $(\text { Mean })^{4}$ & 5,55 & 12,44 & 8,99 & 4,43 & 13,21 & 8,82 \\
\hline $\mathrm{DP}(S D)^{5}$ & 0,56 & 0,86 & 3,75 & 2,51 & 2,08 & 5,09 \\
\hline & \multicolumn{6}{|c|}{$\begin{array}{c}\text { Matéria orgânica do resíduo } \\
\text { insolúvel em etanol (\% da MS) } \\
\text { Ethanol insoluble organic } \\
\text { matter residue (\% of DM) }\end{array}$} \\
\hline 0 & 71,22 & 73,94 & 72,58 & $70,78 \mathrm{Aa}$ & $76,02 \mathrm{Ab}$ & 73,40 \\
\hline 12 & 73,85 & 74,90 & 74,38 & $74,98 \mathrm{Ba}$ & $77,03 \mathrm{Ab}$ & 76,01 \\
\hline 24 & 73,85 & 76,61 & 75,23 & $76,69 \mathrm{Cb}$ & $77,73 \mathrm{Bb}$ & 77,21 \\
\hline 36 & 77,14 & 81,50 & 79,32 & $79,10 \mathrm{Db}$ & $80,11 \mathrm{Cb}$ & 79,61 \\
\hline Média $(\text { Mean })^{4}$ & 74,02 & 76,74 & 75,38 & 75,39 & 77,72 & 76,56 \\
\hline $\mathrm{DP}(S D)^{5}$ & 2,42 & 3,36 & 3,08 & 3,16 & 1,79 & 2,83 \\
\hline
\end{tabular}

1 Tempo de exposição ao ar antes da ensilagem.

2 Grão completamente leitoso.

3 Grão $1 / 2$ leitoso $1 / 2$ farináceo.

4 Médias seguidas por letras diferentes, minúsculas na coluna e maiúsculas na linha, são estatisticamente $(P<0,05)$ diferentes.

5 Desvio-padrão.

1 Periods of air exposure prior to ensiling.

2 Milky kernel.

$31 / 2$ milky $1 / 2$ dough kernel.

${ }^{4}$ Means followed by different small letters in rows and capital letters in columns differ $(P<0.05)$

5 Standard deviation. 
das para a análise de carboidratos. Portanto, o aumento dessa fração pela exposição aeróbia anterior à ensilagem indica degradação de glicídios que, posteriormente, poderão faltar para a otimização da fermentação no silo e/ou no rúmen.

As diferenças numéricas entre os teores de FDN e FDNcp (Tabela 3) são resultantes da subtração das cinzas e PIDN na FDNcp, cujas amplitudes indicam a importância dessas correções para classificação das silagens quanto à qualidade. Porém, na maior parte da bibliografia nacional sobre silagem de milho, muitas vezes, os autores não indicam o procedimento de determinação do teor de FDN, não permitindo ao leitor inferir se é uma silagem de boa ou de média qualidade, visto que esta variação pode facilmente chegar a 5 ou $6 \%$. As diferenças entre FDN e FDNcp têm maior amplitude quanto menor a qualidade nutricional do alimento, geralmente porque essas frações apresentam menores teores de matéria orgânica. Londoño Hernández et al. (2002) observaram diferenças de 2,22 e 1,39\% entre FDN e FDNcp, respectivamente, para silagem de milho confeccionada sem ou com adição de inoculante bacteriano.

Mühlbach (2003), ao comparar os teores de FDN de silagens de milho da literatura nacional com dados da literatura americana e européia, verificou diferenças de 15 a 25 unidades percentuais a mais para silagem de milho produzida no Brasil, o que, segundo o autor, requer ajustes não só no modo de expressar o teor de FDN, mas provavelmente nos procedimentos de produção das silagens de milho, especialmente quando elaboradas para ruminantes de alta produção, que requerem volumosos com baixo teor de FDN. Todavia, segundo Noguera (2002), somente as análises químicas dos alimentos não explicam todos os aspectos da digestão nos ruminantes, pois, além das informações sobre os teores de celulose, hemicelulose, pectina e lignina nas forrageiras, seria necessário conhecer também a distribuição destes constituintes dentro da parede celular.

Pela análise dos efeitos do tempo de exposição ao ar antes da ensilagem para ambos os estádios de maturação (Tabelas 3 e 4), verifica-se que a permanência ao ar sem compactação foi maléfica para a parede celular, incrementando os teores de FDN, FDNcp, FDA e LDA. Os teores de FDNcp aumentaram 4,72 e 1,81 pontos percentuais nas primeiras 12 horas de aeração e 8,19 e 8,52 pontos percentuais nas 36 horas de exposição ar, respectivamente, para os tratamentos GL e GF. Rotz \& Muck (1994) afirmam que a soma das perdas físicas ou a exaustão de nutrientes como os carboidratos solúveis ocasionam aumentos de 3 a $12 \%$ no teor de FDN na MS das silagens produzidas.

Comparando-se os teores de FDNcp da Tabela 3 para os estádios GL e GF no tempo zero hora, verifica-se que somente o processo fermentativo no silo foi suficiente para
Tabela 3 - Teores médios de FDN e FDNcp da matéria verde e das silagens

Table 3 - $\quad$ Average contents of NDF and NDFap of fresh material and silages

\begin{tabular}{|c|c|c|c|c|c|c|}
\hline \multirow[t]{3}{*}{$\begin{array}{l}\text { Período } 1 \\
\text { Period }\end{array}$} & \multicolumn{3}{|c|}{$\begin{array}{l}\text { Matéria verde } \\
\text { Fresh material }\end{array}$} & \multicolumn{3}{|c|}{$\begin{array}{l}\text { Silagem } \\
\text { Silage } \\
\end{array}$} \\
\hline & $\mathrm{GL}^{2}$ & $\mathrm{GF}^{3}$ & Média & $\mathrm{GL}^{2}$ & $\mathrm{GF}^{3}$ & Média ${ }^{4}$ \\
\hline & $M K$ & $M D K$ & Mean & $M K M$ & $D K$ & Mean \\
\hline & \multirow{2}{*}{\multicolumn{6}{|c|}{$\begin{array}{l}\text { FDN (\% da MS) } \\
N D F(\% \text { of } D M)\end{array}$}} \\
\hline & & & & & & \\
\hline 0 & 59,53 & 51,95 & 55,74 & $62,22 \mathrm{Ab}$ & $53,50 \mathrm{Aa}$ & 57,86 \\
\hline 12 & 64,54 & 54,98 & 59,76 & $67,00 \mathrm{Bb}$ & $55,04 \mathrm{Ba}$ & 61,02 \\
\hline 24 & 64,43 & 56,88 & 60,66 & $70,93 \mathrm{Cb}$ & $59,59 \mathrm{Ca}$ & 65,26 \\
\hline 36 & 69,09 & 63,01 & 66,05 & $73,49 \mathrm{Db}$ & $59,52 \mathrm{Ca}$ & 66,51 \\
\hline Média $(\text { Mean })^{4}$ & 64,40 & 56,71 & 60,55 & 68,41 & 56,91 & 62,66 \\
\hline \multirow[t]{3}{*}{$\mathrm{DP}(S D)^{5}$} & 3,90 & 4,67 & 5,73 & 4,46 & 2,89 & 6,75 \\
\hline & \multirow{2}{*}{\multicolumn{6}{|c|}{$\begin{array}{c}\text { FDNcp }(\% \text { da MS) } \\
\text { NDFap }(\% \text { of DM) }\end{array}$}} \\
\hline & & & & & & \\
\hline 0 & 55,24 & 49,95 & 52,60 & $60,79 \mathrm{Ab}$ & $52,57 \mathrm{Aa}$ & 56,68 \\
\hline 12 & 59,96 & 51,76 & 55,86 & $65,46 \mathrm{Bb}$ & $53,82 \mathrm{Aa}$ & 59,64 \\
\hline 24 & 60,22 & 52,96 & 56,59 & $69,05 \mathrm{Cb}$ & $57,88 \mathrm{Ba}$ & 63,47 \\
\hline 36 & 63,43 & 58,47 & 60,95 & $71,02 \mathrm{Db}$ & $57,94 \mathrm{Ba}$ & 64,48 \\
\hline Média $(\text { Mean })^{4}$ & 59,71 & 53,29 & 56,50 & 66,58 & 55,55 & 61,07 \\
\hline $\mathrm{DP}(S D)^{5}$ & 3,37 & 3,67 & 4,74 & 4,09 & 2,57 & 6,39 \\
\hline
\end{tabular}

1 Tempo de exposição ao ar antes da ensilagem.

2 Grão completamente leitoso.

3 Grão $1 / 2$ leitoso $1 / 2$ farináceo.

4 Médias seguidas por letras diferentes, minúsculas na coluna e maiúsculas na linha, são estatisticamente $(P<0,05)$ diferentes.

5 Desvio-padrão.

1 Periods of air exposure prior to ensiling.

2 Milky kernel.

$31 / 2$ milky $1 / 2$ dough kernel.

${ }^{4}$ Means followed by different small letters in rows and capital letters in columns differ $(P<0.05)$.

5 Standard deviation.

elevar os teores de FDNcp de 55,24 para $60,79 \%$ e de 49,95 para $52,57 \%$ respectivamente, demonstrando que o ponto de corte influencia preponderantemente o valor nutricional da silagem produzida.

Contudo, estas variações decorrentes da fermentação podem ser minimizadas acelerando o processo fermentativo pela adição de inoculantes adequados objetivando antecipar a paralisação da respiração celular e a conseqüente "queima" de açúcares solúveis por meio da diminuição do $\mathrm{pH}$ e da exclusão do oxigênio. Porém, quando o processo de ensilagem é inadequado, por lentidão no enchimento do silo ou pela falta de compactação, o aumento nos teores de FDNcp é desastroso, ainda mais acentuado que nas condições deste trabalho, em que foram pré-estabelecidas para simular manejo inadequado no processo de ensilagem.

No tratamento GL (Tabela 3), o aumento nas primeiras 12 horas de exposição ao ar foi de 4,78 e 4,67 unidades percentuais, respectivamente, para FDN e FDNcp e, nesta mesma ordem, o aumento até 36 horas de exposição ao ar foi de 11,27 e 10,23 unidades percentuais. Para o tratamento GF, a variação nos teores de FDN e FDNcp nas primeiras 12 
Tabela 4 - Teores médios de FDA e LIG da matéria verde e das silagens

Table 4 - Average contents of ADF and LIG of fresh material and silages

\begin{tabular}{|c|c|c|c|c|c|c|}
\hline \multirow[t]{2}{*}{$\begin{array}{l}\text { Período } \\
\text { Period }\end{array}$} & \multicolumn{3}{|c|}{$\begin{array}{l}\text { Matéria verde } \\
\text { Fresh material }\end{array}$} & \multicolumn{3}{|c|}{$\begin{array}{c}\text { Silagem } \\
\text { Silage }\end{array}$} \\
\hline & $\mathrm{GL}^{2}$ & $\mathrm{GF}^{3}$ & Média & $\mathrm{GL}^{2}$ & $\mathrm{GF}^{3}$ & Média 4 \\
\hline & $M K$ & $M D K$ & Mean & $M K M$ & $D K$ & Mean \\
\hline
\end{tabular}

FDA (\% da MS)

$A D F(\%$ of $D M)$

\begin{tabular}{lllllll}
0 & 30,87 & 26,06 & 28,47 & $34,02 \mathrm{Ab}$ & $28,49 \mathrm{Aa}$ & 31,26 \\
12 & 32,37 & 27,65 & 30,01 & $35,78 \mathrm{Bb}$ & $28,95 \mathrm{Aa}$ & 32,37 \\
24 & 32,43 & 28,09 & 30,26 & $37,04 \mathrm{Cb}$ & $30,62 \mathrm{Ba}$ & 33,83 \\
36 & 33,43 & 30,26 & 31,85 & $37,60 \mathrm{Cb}$ & $30,34 \mathrm{Ba}$ & 33,97 \\
Média $^{4}$ & 32,28 & 28,02 & 30,15 & 36,11 & 29,60 & 32,86 \\
$\begin{array}{l}\text { Mean } \\
\mathrm{DP}^{5}\end{array}$ & 1,06 & 1,73 & 2,64 & 1,50 & 1,04 & 3,49 \\
$S D$ & & & & & & \\
\hline
\end{tabular}

\begin{tabular}{lcccccc}
\hline \multicolumn{7}{c}{ LIG em detergente ácido (\% da MS) } \\
Acid detergent & LIG $\%$ of $D M$ ) \\
0 & 2,85 & 2,44 & 2,65 & 3,06 & 2,74 & $2,90 \mathrm{~A}$ \\
12 & 2,89 & 2,64 & 2,77 & 3,61 & 2,88 & $3,25 \mathrm{~B}$ \\
24 & 3,24 & 2,81 & 3,03 & 3,68 & 3,18 & $3,43 \mathrm{BC}$ \\
36 & 3,30 & 3,11 & 3,21 & 3,99 & 3,22 & $3,61 \mathrm{C}$ \\
Média $^{4}$ & 3,07 & 2,75 & 2,91 & $3,59 \mathrm{~b}$ & $3,01 \mathrm{a}$ & 3,30 \\
Mean & & & & & & \\
$\mathrm{DP}^{5}$ & 0,23 & 0,28 & 0,29 & 0,37 & 0,30 & 0,43 \\
SD & & & & & &
\end{tabular}

1 Tempo de exposição ao ar antes da ensilagem.

2 Grão completamente leitoso.

3 Grão $1 / 2$ leitoso $1 / 2$ farináceo.

4 Médias seguidas por letras diferentes, minúsculas na coluna e maiúsculas na linha, são estatisticamente $(P<0,05)$ diferentes.

5 Desvio-padrão.

1 Periods of air exposure prior to ensiling.

2 Milky kernel.

$31 / 2$ milky $1 / 2$ dough kernel.

${ }^{4}$ Means followed by different small letters in rows and capital letters in columns differ $(P<0.05)$.

5 Standard deviation

horas foi de 1,54 e 1,25 unidades percentuais e, após 36 horas, foi de 6,02 e 5,37 unidades, respectivamente. Portanto, os aumentos decorrentes dos crescentes tempos de exposição da massa verde ao ar sem compactação antes da ensilagem tornaram as silagens produzidas impróprias para alimentação de animais de alta produção, mesmo no GF, com menor magnitude de incremento. Segundo Mertens (1994), em revisão sobre regulação do consumo de forragem, a distensão do retículo-rúmen tem sido aceita como o fator que mais limita o consumo de dietas ricas em fibra, de modo que, quanto maior a proporção de fibra nos alimentos volumosos, maior a limitação do consumo e, conseqüentemente, menor a produção de leite e/ou carne.

Quando se compara o teor de FDNcp inicial no momento da colheita, nos estádios GL (55,24\%) e GF (49,95\%), com a silagem produzida após as 36 horas de aeração (Tabela 3 ), a variação no teor de FDNcp, em ambos os estádios, é, respectivamente, de 15,78 e 7,99 pontos percentuais, inviabilizando o uso destas silagens, visto que, para reduzir o teor de FDN da dieta, é necessário aumentar a proporção de concentrado, que apresenta custos mais elevados, diminuindo a margem de lucro da atividade na propriedade rural.

Os valores observados de FDN e FDNcp (Tabela 3) para o GL são muito maiores que os tabelados pelo NRC (2001) para silagem de milho imatura $(54,1 \%)$ com menos de $25 \%$ de MS. Os teores de FDNcp e FDA do tratamento GL (Tabelas 3 e 4) estão de acordo com os dados revisados e tabelados por Johnson et al. (1999) para grão completamente leitoso, de 64,3 e $35,6 \%$, respectivamente. No tratamento GF, o valor de FDA (Tabela 4) foi inferior ao reportado por Johnson et al. (1999) e a FDNcp foi, em média, 10,5 pontos percentuais acima do valor reportado $(45,0 \%$ da MS) pelos autores. Desde o momento da colheita das plantas no GL até a abertura dos silos do tratamento 36 horas, o teor de FDA aumentou 6,73 pontos percentuais e, no GF, aumentou 4,28 pontos percentuais. O incremento do teor de FDA foi acompanhado por significativos $(\mathrm{P}<0,05)$ aumentos nos teores de lignina à medida que o tempo de exposição ao ar progrediu.

$O$ teor de LAD (Tabela 4) apresentou efeito significativo $(\mathrm{P}<0,05)$, aumentando com o passar do tempo ( 0 até 36 horas). Apesar desse incremento, os teores de LAD ficaram aquém dos valores observados para silagem de milho por Cabral et al. (2000), de 4,37\% da MS, e Londoño Hernández et al. (2002), de 5,35 a 5,29\% da MS, respectivamente, para silagem sem e com inoculante. São semelhantes aos valores reportados por Campos et al. (2001), de 3,6\% da MS para silagem com $29,6 \%$ de MS

Segundo Dias (2002), as duas frações que mais representam a planta de milho são a FDN e o amido. Qualquer alteração nesses dois parâmetros resulta em grandes alterações no valor nutricional da planta de milho. Esta afirmação do autor se confirmou neste trabalho pelas interações dos efeitos principais sobre o teor de carboidratos totais, carboidratos não-estruturais e nas frações A, B1 e B2 (Tabelas 5 e 6), derivadas fundamentalmente dos teores de amido e FDN.

Os valores de carboidratos totais (Tabela 5) foram semelhantes aos obtidos por Backes et al. (2000) para silagens de milho de planta inteira sem $(87,25 \%)$ e com inoculante $(89,11 \%)$, porém, no fracionamento dos carboidratos, foram diferentes (Sniffen et al., 1992). Backes et al. (2000) obtiveram 15,42 e 15,83\%; 12,67 e 11,28\%; 49,60 e 53,88\%; 9,56 e 8,12\%, respectivamente, para as frações A, $\mathrm{B}_{1}, \mathrm{~B}_{2}$ e C para as silagens sem e com inoculante. Conforme Sniffen et al. (1992), os carboidratos podem ser classificados de acordo com as taxas de degradação: fração A (açúcares solúveis) - rápida degradação; fração $\mathrm{B}_{1}$ (amido) - média degradação; fração $\mathrm{B}_{2}$ (parede celular disponível) - lenta degradação; e Fração C (parede celular indigestível) 
Tabela 5 - Teores médios de CT e CNE da matéria verde e das silagens

Table 5 - $\quad$ Average contents of CHOT and NCS of fresh material and silages

\begin{tabular}{|c|c|c|c|c|c|c|}
\hline \multirow[t]{3}{*}{$\begin{array}{l}\text { Período } \\
\text { Period }\end{array}$} & \multicolumn{3}{|c|}{$\begin{array}{l}\text { Matéria verde } \\
\text { Fresh material }\end{array}$} & \multicolumn{3}{|c|}{$\begin{array}{l}\text { Silagem } \\
\text { Silage }\end{array}$} \\
\hline & $\mathrm{GL}^{2}$ & $\mathrm{GF}^{3}$ & Média & $\mathrm{GL}^{2}$ & $\mathrm{GF}^{3}$ & Média ${ }^{4}$ \\
\hline & $M K$ & $M D K$ & Mean & $M K M$ & $D K$ & Mean \\
\hline & \multicolumn{6}{|c|}{$\begin{array}{c}\text { Carboidratos totais }(\% \text { da } \mathrm{MS}) \\
\text { Total carbohydrates }(\% \text { of } D M)\end{array}$} \\
\hline 0 & 85,64 & 87,74 & 86,69 & $85,21 \mathrm{Aa}$ & $85,92 \mathrm{Aba}$ & 85,57 \\
\hline 12 & 86,14 & 86,85 & 86,50 & $83,97 \mathrm{BCa}$ & $86,39 \mathrm{Ab}$ & 85,18 \\
\hline 24 & 86,53 & 86,64 & 86,59 & $84,76 \mathrm{Aba}$ & $85,52 \mathrm{Aba}$ & 85,14 \\
\hline 36 & 85,07 & 86,16 & 85,62 & $83,48 \mathrm{Ca}$ & $85,33 \mathrm{Bb}$ & 84,41 \\
\hline Média ${ }^{4}$ & 85,85 & 86,85 & 86,35 & 84,36 & 85,79 & 85,08 \\
\hline Mean & & & & & & \\
\hline $\begin{array}{l}\mathrm{DP}^{5} \\
S D\end{array}$ & 0,63 & 0,66 & 0,80 & 0,93 & 0,62 & 1,04 \\
\hline
\end{tabular}

Carboidratos não-estruturais (\% dos CT) Non-structural carbohydrates (\% of TC)

\begin{tabular}{lllllll}
0 & 34,49 & 43,01 & 38,75 & $30,21 \mathrm{Ab}$ & $39,21 \mathrm{Aa}$ & 34,71 \\
12 & 28,96 & 39,48 & 34,22 & $23,92 \mathrm{Bb}$ & $38,08 \mathrm{Aa}$ & 31,00 \\
24 & 29,20 & 37,77 & 33,49 & $19,16 \mathrm{Cb}$ & $33,24 \mathrm{Ba}$ & 26,20 \\
36 & 23,99 & 30,74 & 27,37 & $16,83 \mathrm{Cb}$ & $33,50 \mathrm{Ba}$ & 25,17 \\
Média $^{4}$ & 29,16 & 37,75 & 33,46 & 22,53 & 36,01 & 29,27 \\
$\begin{array}{l}\text { Mean } \\
\mathrm{DP}^{5}\end{array}$ & 4,29 & 5,16 & 6,35 & 5,56 & 2,92 & 7,93 \\
$S D$ & & & & & & \\
\hline
\end{tabular}

1 Tempo de exposição ao ar antes da ensilagem.

2 Grão completamente leitoso.

3 Grão $1 \frac{1}{2}$ leitoso $1 / 2$ farináceo.

4 Médias seguidas por letras diferentes, minúsculas na coluna e maiúsculas na linha, são estatisticamente $(P<0,05)$ diferentes.

5 Desvio-padrão.

1 Periods of air exposure prior to ensiling.

2 Milky kernel.

$31 / 2$ milky $1 / 2$ dough kernel.

4 Means followed by different small letters in rows and capital letters in columns differ $(P<0.05)$.

${ }^{5}$ Standard deviation

- indegradável. Portanto, a silagem produzida por Backes et al. (2000) apresentava maior valor nutricional por possuir menores proporções de carboidratos estruturais (frações $\left.\mathrm{B}_{2}+\mathrm{C}\right)$.

Comparando-se os dados da Tabela 6 aos valores obtidos por Mello \& Nörnberg (2004), em híbridos de milho na Depressão Central do Rio Grande do Sul, as quantidades de carboidratos totais (CT) de $85,9 \%$ na MS foram semelhantes, enquanto a fração carboidratos não-estruturais (CNE) foi levemente superior à relatada por esses autores $(42,47 \% \operatorname{dos} \mathrm{CT})$.

\section{Conclusões}

O milho "safrinha" colhido no estádio $1 / 2$ leitoso $1 \frac{1}{2}$ farináceo com maior acúmulo de carboidratos não-estruturais e menor teor de FDNcp apresentou melhor condição para ensilagem que no estádio de grão leitoso.
Tabela 6 - Fracionamento dos carboidratos segundo Sniffen et al. (1992) da matéria verde e das silagens

Table 6 - Carbohydrate fractionation of fresh material and silages according to Sniffen et al. (1992)

\begin{tabular}{|c|c|c|c|c|c|c|}
\hline \multirow[t]{3}{*}{$\begin{array}{l}\text { Período } \\
\text { Period }\end{array}$} & \multicolumn{3}{|c|}{$\begin{array}{l}\text { Matéria verde } \\
\text { Fresh material }\end{array}$} & \multicolumn{3}{|c|}{$\begin{array}{l}\text { Silagem } \\
\text { Silage }\end{array}$} \\
\hline & $\mathrm{GL}^{2}$ & $\mathrm{GF}^{3}$ & Média & $\mathrm{GL}^{2}$ & $\mathrm{GF}^{3}$ & Média ${ }^{4}$ \\
\hline & & $M D K$ & Mean & $M K M$ & $D K$ & Mean \\
\hline & \multicolumn{6}{|c|}{$\begin{array}{c}\text { Fração A }(\% \text { dos CT }) \\
\text { Fraction } A(\% T C)\end{array}$} \\
\hline 0 & 28,67 & 31,31 & 29,99 & $27,07 \mathrm{Aa}$ & $24,90 \mathrm{Ab}$ & 25,99 \\
\hline 12 & 23,93 & 26,01 & 24,97 & $21,59 \mathrm{Ba}$ & $23,75 \mathrm{Aba}$ & 22,67 \\
\hline 24 & 22,99 & 25,95 & 24,49 & $14,36 \mathrm{Cb}$ & $20,12 \mathrm{Ba}$ & 17,24 \\
\hline 36 & 18,86 & 17,94 & 18,40 & $9,39 \mathrm{Db}$ & $22,42 \mathrm{Aba}$ & 15,91 \\
\hline Média $^{4}$ & 23,61 & 25,31 & 24,46 & 18,10 & 22,80 & 20,45 \\
\hline $\begin{array}{l}\text { Mean } \\
\text { DP } 5\end{array}$ & & & & & & \\
\hline $\begin{array}{l}\mathrm{D} \mathrm{P}^{3} \\
S D\end{array}$ & 4,03 & 5,52 & 4,56 & 7,26 & 2,35 & 5,63 \\
\hline
\end{tabular}

Fração $\mathrm{B}_{1}(\%$ dos $\mathrm{CT})$

Fraction $B_{1}(\% T C)$

$\begin{array}{lllllll}0 & 5,81 & 11,70 & 8,76 & 3,14 \mathrm{Bb} & 14,31 \mathrm{Aa} & 8,73 \\ 12 & 5,03 & 13,48 & 9,26 & 2,34 \mathrm{Bb} & 14,33 \mathrm{Aa} & 8,34 \\ 24 & 6,21 & 11,78 & 9,00 & 4,80 \mathrm{Bb} & 13,12 \mathrm{Aa} & 8,96 \\ 36 & 5,13 & 12,80 & 8,97 & 7,44 \mathrm{Aa} & 11,07 \mathrm{Aa} & 9,26 \\ \text { Média }^{4} & 5,55 & 12,44 & 8,99 & 4,43 & 13,21 & 8,82 \\ \begin{array}{l}\text { Mean } \\ \mathrm{DP}^{5}\end{array} & 0,56 & 0,86 & 3,75 & 2,51 & 2,08 & 5,09 \\ S D & & & & & & \end{array}$

\begin{tabular}{|c|c|c|c|c|c|c|}
\hline \multirow[b]{2}{*}{0} & \multicolumn{6}{|c|}{$\begin{array}{c}\text { Fração } B_{2}(\% \text { dos CT }) \\
\text { Fraction } B_{2}(\% \text { TC })\end{array}$} \\
\hline & 57,59 & 50,35 & 53,97 & $61,23 \mathrm{Ab}$ & $53,15 \mathrm{Aa}$ & 57,19 \\
\hline 12 & 63,05 & 53,29 & 58,17 & $65,84 \mathrm{Bb}$ & $53,95 \mathrm{Aa}$ & 59,90 \\
\hline 24 & 61,88 & 54,50 & 58,19 & $70,46 \mathrm{Cb}$ & $57,88 \mathrm{Ba}$ & 64,17 \\
\hline 36 & 66,79 & 60,67 & 63,73 & $71,79 \mathrm{Cb}$ & $57,49 \mathrm{Ba}$ & 64,64 \\
\hline Média $^{4}$ & 62,33 & 54,70 & 58,52 & 67,33 & 55,62 & 61,48 \\
\hline $\begin{array}{l}\text { Mean } \\
\mathrm{DP}^{5} \\
S D\end{array}$ & 3,79 & 4,34 & 5,55 & 4,56 & 2,48 & 6,81 \\
\hline \multicolumn{7}{|c|}{$\begin{array}{c}\text { Fração C }(\% \text { dos CT }) \\
\text { Fraction C }(\% T C)\end{array}$} \\
\hline 0 & 7,92 & 6,64 & 7,28 & 8,56 & 7,64 & $8,10 \mathrm{~A}$ \\
\hline 12 & 7,98 & 7,23 & 7,61 & 10,24 & 7,97 & $9,11 \mathrm{~B}$ \\
\hline 24 & 8,92 & 7,73 & 8,33 & 10,38 & 8,88 & $9,63 \mathrm{BC}$ \\
\hline 36 & 9,23 & 8,58 & 8,91 & 11,37 & 9,01 & $10,19 \mathrm{C}$ \\
\hline Média $^{4}$ & 8,51 & 7,55 & 8,03 & $10,14 b$ & $8,38 \mathrm{a}$ & 9,26 \\
\hline $\begin{array}{l}\text { Mean } \\
\mathrm{DP}^{5} \\
S D\end{array}$ & 0,66 & 0,82 & 0,86 & 1,12 & 0,85 & 1,29 \\
\hline
\end{tabular}

1 Tempo de exposição ao ar antes da ensilagem.

2 Grão completamente leitoso.

3 Grão $1 / 2$ leitoso $1 / 2$ farináceo.

${ }^{4}$ Médias seguidas por letras diferentes, minúsculas na coluna e maiúsculas na linha, são estatisticamente $(P<0,05)$ diferentes.

5 Desvio-padrão.

1 Periods of air exposure prior to ensiling.

2 Milky kernel.

$31 / 2$ milky $1 / 2$ dough kernel.

${ }^{4}$ Means followed by different small letters in rows and capital letters in columns differ $(P<0.05)$.

5 Standard deviation.

As perdas e alterações ocasionadas pela demora no enchimento e vedação do silo podem inviabilizar o uso da silagem para animais de alta produção, em razão do aumento 
nas frações de parede celular e da diminuição das proporções dos carboidratos não-estruturais desse alimento.

\section{Agradecimento}

Ao Conselho Nacional de Desenvolvimento Científico e Tecnológico, pelos recursos financeiros e pelas bolsas de estudo concedidas para o desenvolvimento deste trabalho.

\section{Literatura Citada}

BACKES, A.A.; BONNECARRÈRE SANCHEZ, L.M.; GONÇALVES, M.B.F. et al. Determinação das frações da proteína e carboidratos de alguns alimentos conforme metodologia do CNCPS (Cornell Net Carbohydrate and Protein System). In: REUNIÃO ANUAL DA SOCIEDADE BRASILEIRA DE ZOOTECNIA, 37., 2000, Viçosa. Anais... São Paulo: Sociedade Brasileira de Zootecnia/ Gnosis, [2000] CD-ROM. Nutrição de Ruminantes 0913.

CABRAL, L.S.; VALADARES FILHO, S.C.; MALAFAIA, P.A.M. et al. Frações de carboidratos de alimentos volumosos e suas taxas de degradação estimadas pela técnica de produção de gases. Revista Brasileira de Zootecnia, v.29, n.6, p.2087-2098, 2000 (supl. 1).

CAMPOS, F.P.; SAMPAIO, A.A.M.; VIEIRA, P.F. et al. Digestibilidade in vitro/gás de volumosos exclusivos ou combinados avaliados pelo resíduo remanescente da digestão da matéria seca e produção de gás. Revista Brasileira de Zootecnia, v.30, n5, p.1579-1589, 2001.

DIAS, F.N. Avaliação de parâmetros agronômicos e nutricionais em híbridos de milho (Zea mays L.) para silagem. Piracicaba: Escola Superior de Agricultura Luiz de Queiroz, 2002. 96p. Dissertação (Mestrado em Agronomia) Escola Superior de Agricultura Luiz de Queiroz, 2002.

FERREIRA, J.J. Estágio de maturação ideal para ensilagem do milho e do sorgo. In: CRUZ, J.C.; PEREIRA FILHO, I.A.; RODRIGUES, J.A.S.et al. (Eds.) Produção e utilização de silagem de milho e sorgo. Sete Lagoas: Embrapa Milho e Sorgo, 2001. p.405-428.

HALL, M.B.; LEWIS, B.A.; Van SOEST, P.J. et al. A simple method for estimation of neutral detergent-soluble fibre. Journal Science Food Agricultural, v.74, p.441-449, 1997.

HALL, M.B. Neutral detergent-soluble carbohydrates, nutritional relevance and analysis. A laboratory manual. Florida: University of Florida, 2000. 42p. (Bulletin 339)

JOHNSON, L.; HARISSON, J.H.; HUNT, C. et al. Nutritive value of corn silage as affected by maturity and mechanical processing: A contemporary review. Journal of Dairy Science, v. 82, n.12, p.2813-2825, 1999.

LONDOÑO HERNÁNDEZ, F.I.; VALADARES FILHO, S.C.; PAULINO, M.F. et al. Avaliação da composição de vários alimentos e determinação da cinética ruminal da proteína, utilizando o método de produção de gás e amônia in vitro. Revista Brasileira de Zootecnia, v.31, n1, p.243-255, 2002 .

MELLO, R.; NÖRNBERG, J.L. Fracionamento dos carboidratos e proteínas de silagens de milho, sorgo e girassol. Ciência Rural, v.34, n5, p.1537-1542, 2004.

MERTENS, D.R. Challenges in measuring insoluble dietary fiber. Journal of Animal Science, v.81, n.12, p.3233-3249, 2003.

MERTENS, D.R. Gravimetric determination of amylase-treated neutral detergent fiber in feeds with refluxing in beakers or crucibles: collaborative study. Journal of AOAC International, v. 85, n.6, p.1217-1240, 2002.

MERTENS, D.R. Regulation of forage intake. In: FAHEY JR., G.C.; MOSER, L.E.; MERTENS, D.R. et al. (Eds.) National conference on forage quality, evaluation, and utilization. Madison: University of Nebraska, 1994. p.450-493.

MOREnO, J.A. Clima do Rio Grande do Sul. Porto Alegre: Secretaria da Agricultura, 1961. 41p.

MUCK, R.E. Factors influencing silage quality and their implications for management. Journal of Dairy Science, v.71, n.11, p.2992-3002, 1988.

MÜHLBACH, P.R.F. Produção de leite com vacas de alta produtividade. In: REUNIÃO ANUAL DA SOCIEDADE BRASILEIRA DE ZOOTECNIA, 40., 2003, Santa Maria. Anais... São Paulo: Sociedade Brasileira de Zootecnia/Infovia, [2003]. CD-ROM. Palestras Sessão Bovinocultura de Leite.

NATIONAL RESEARCH COUNCIL - NRC. Nutrient requirements of dairy cattle. 7.rev.ed. Washington D.C.: National Academy Press, 2001. 360p.

NOGUERA, J.R.R. Estudo químico in situ, in vitro e microscópico da parede celular de cinco genótipos de sorgo colhidos em três épocas de corte. Belo Horizonte: Universidade Federal de Minas Gerais, 2002. 177p. Tese (Doutorado em Ciência Animal) - Universidade Federal de Minas Gerais, 2002.

OBA, M.; ALLEN, M.S. Effects of brown midrib 3 mutation in corn silage on productivity of dairy cows fed two concentrations of dietary neutral detergent fiber: 1 . Feeding behavior and nutrient utilization. Journal of Dairy Science, v. 83, n6, p.1333-1341, 2000

RODRIGUES, P.H.M.; RUZANTE, J.M.; SENATORE, A.L. et al. Avaliação do uso de inoculantes microbianos sobre a qualidade fermentativa e nutricional da silagem de milho. Revista Brasileira de Zootecnia, v.33, n.3, p.538-545, 2004

ROTZ, C.A.; MUCK, R.E. Changes in forage quality during harvest and storage. In: FAHEY Jr., G.C.; MOSER, L.E.; MERTENS, D.R. et al. (Eds.) National conference on forage quality, evaluation, and utilization. Madison: University of Nebraska, 1994. p.828-868.

SENGER, C.C.D.; MÜHLBACH, P.R.F.; BONNECARRÈRE SANCHEZ, L.M. et al. Composição e digestibilidade 'in vitro' de silagens de milho com distintos teores de umidade e níveis de compactação. Ciência Rural, v.35, n.6, p.1393-1399, 2005.

SENGER, C.C.D.; MÜHLBACH, P.R.F.; BONNECARRÈRE SANCHEZ, L.M. et al. Influência da umidade e compactação sobre os carboidratos estruturais e glicídios solúveis de silagens de milho. In: REUNIÃO ANUAL DA SOCIEDADE BRASILEIRA DE ZOOTECNIA, 41., 2004, Campo Grande. Anais... Campo Grande: Sociedade Brasileira de Zootecnia, [2004] CD-ROM. Nutrição de Ruminantes 101.

SILVA, D.J.; QUEIROZ, A.C. Análise de alimentos: métodos químicos e biológicos. Viçosa, MG: Universidade Federal de Viçosa, 2002. 235p.

SNIFFEN, C.J.; O'CONNOR, J.D.; Van SOEST, P.J. et al. A net carbohydrate and protein system for evaluating cattle diets: II. Carbohydrate and protein availability. Journal Animal Science, v.70, n.11, p.3562-3577, 1992.

SPSS. Base 10.0 Applications Guide Copyright 1999 by SPSS Inc. Printed in the United States of America.

STRECK, E.V.; KÄMPF, N.; DALMOLIN, R.S.D. et al. Solos do Rio Grande do Sul. Porto Alegre: EMATER/RS; UFRGS, 2002. $107 \mathrm{p}$.

Van SOEST, P.J. Nutritional ecology of the ruminant. Ithaca: Cornell University Press, 1994. 476p.

WALTER, M. Amido resistente: metodologias de quantificação e resposta biológica em ratos. Santa Maria: Universidade Federal de Santa Maria, 2005. 96p. Dissertação (Mestrado em Ciência e Tecnologia de Alimentos) - Universidade Federal de Santa Maria, 2005.
Recebido: 19/09/05 Aprovado: 15/03/06 